\section{Military Technical College Kobry El-Kobbah, Cairo, Egypt}

\section{$8^{\text {th }}$ International Conference on Electrical Engineering ICEENG 2012}

\title{
Power frequency electromagnetic field exposure assessment
}

By

\author{
H. S. Seddeq * \\ G. A. Khawas **
}

\section{$\underline{\text { Abstract: }}$}

Power frequency electromagnetic fields are receiving growing attention in recent years because of concerns that exposure to such fields might cause or contribute to adverse health effects. This paper reviewed the international limits for electromagnetic field exposure. Also this paper presented the problem with existing standards limits for electromagnetic field exposure and showed that these limits are not safety for public health risks. As a case study was investigated and evaluated to assess the power frequency electromagnetic fields exposure from electrical equipments, transmission lines and LED display in commercial building according to existing and the suggested healthy limits.

\section{Keywords:}

Power frequency electromagnetic fields, extremely low-frequency, Electromagnetic field exposure limits, transmission lines

* Housing \& Building Research Center, Building Physics Department, Egypt

** Housing \& Building Research Center, Building Physics Department, Egypt 


\section{Introduction:}

Exposure to electromagnetic fields is not a new phenomenon. However, during the 20th century, environmental exposure to man-made electromagnetic fields has been steadily increasing as growing demand for electricity, ever-advancing technologies and changes in social behavior have created more and more artificial sources. While the enormous benefits of using electricity in everyday life, health care are unquestioned. Power frequency electromagnetic fields (EMF) are generated in the production, transport, distribution and use of electricity. The interest in this case are the electric and magnetic fields (EMF) in the extreme low-frequency range that includes the power frequency of $50 \mathrm{~Hz}$. Magnetic fields of extremely low-frequency (ELF) range $(3-3000 \mathrm{~Hz})$ are mostly associated with man-made sources such as electrical and electronic appliances and power lines. In large commercial buildings when offices and work areas are located near electrical systems such as transformers, network protectors, secondary feeders, switchgears, and electrical panels, the occupants are usually exposed to $50-\mathrm{Hz}$ (Hertz) magnetic field levels. Because human beings are bioelectrical systems, there are an increasing concern that exposure to EMF may be associated with biological and health effects. Environmental exposures to artificial electromagnetic fields, EMFs can interact with fundamental biological processes in the human body and may cause discomfort and disease. Many studies and reports concluded that exposure to magnetic fields of extremely low-frequency (ELF) can harm health $[1,2]$.

\section{Electromagnetic field exposure guidelines limits:}

Generally accepted guidelines have been established for safe public and occupational exposure to power-frequency electromagnetic fields. The international organization established reference levels for exposure to electromagnetic fields- of low frequency. Table (1) shows comparison of exposure guideline limits for $50-\mathrm{Hz}$ magnetic fields established by International Commission on Non-Ionizing Radiation Protection (ICNIRP), Institute of Electrical and Electronics Engineers (IEEE) and European Communities.

The American Conference of Governmental Industrial Hygienists (ACGIH) recommends $10,000 \mathrm{mG}(1000 \mu \mathrm{T})$ and $25 \mathrm{kV} / \mathrm{m}$ for occupational workers. Lower levels of $1,000 \mathrm{mG}$ and $1 \mathrm{kV} / \mathrm{m}$ are recommended by the ACGIH for occupational workers with cardiac pacemakers. New York and Florida have set $200 \mathrm{mG}$ right-of-way (ROW) limits for new transmission lines. Also, the City of Irvine, California, and Brentwood, Tennessee, set $4 \mathrm{mG}$ acceptable human exposure limits. Unfortunately, due to the conflicting scientific research and lack of governmental standards, it is recommended to establish an acceptable human exposure limits [8]. 
Table (1): Comparison of exposure limits for $50 \mathrm{~Hz}$ Magnetic field in $\mathrm{mG}$

\begin{tabular}{|c|c|c|c|c|c|}
\hline \multirow{2}{*}{$\begin{array}{c}\text { EMF } \\
\text { Exposure }\end{array}$} & \multirow{2}{*}{$\begin{array}{l}\text { ICNIRP } \\
1998[3]\end{array}$} & \multirow{2}{*}{$\begin{array}{l}\text { ICNIRP } \\
2002[4]\end{array}$} & \multirow{2}{*}{$\begin{array}{c}\text { IEEE } \\
{[5]}\end{array}$} & \multicolumn{2}{|c|}{ European Communities $[6,7]$} \\
\hline & & & & $\begin{array}{l}\text { Recommendation } \\
\text { 1999/519/EC }\end{array}$ & $\begin{array}{l}\text { Directive } \\
\text { 2004/40/EC }\end{array}$ \\
\hline Occupational & 5000 & 10000 & 27100 & - & 5000 \\
\hline $\begin{array}{l}\text { General } \\
\text { public }\end{array}$ & 1000 & 2000 & 9040 & 1000 & - \\
\hline
\end{tabular}

\section{Problems with existing public health standards (safety limits):}

The international exposure limits for ELF are based on the presumption that induced electric currents flow in the body is the only concerns when living organisms are exposed to ELE. In the last few decades, it has been established beyond any reasonable doubt that bio-effects and some adverse health effects occur at far lower levels ELF exposure where no induced currents occurs at all specially for long term exposure. Some effects have been shown to occur at several hundred thousand times below the existing public safety limits where heating is impossibility occurred so new exposure standards for ELF has to be defined.

Many studies carried out to investigate the effects of ELF magnetic fields on human especially for long term exposure. Some results of these studies are as follows:

- Several recent studies indicate an association between residential and workplace exposure to magnetic fields and the risk of cancer, especially leukemia and brain tumors. They indicate that an excess risk may exist for average exposures exceeding 0.3-0.4 $\mathrm{T}$ [9][10].

- Low-frequency magnetic fields appear to influence some neurophysiologic, behavioral and developmental end points, although most of these effects appear to be completely reversible [11].

- There is some evidence that other childhood cancers may be related to ELF exposure but not enough studies have been done [12]

- The evidence from studies on women in the workplace rather strongly suggests that ELF is a risk factor for breast cancer for women with long-term exposures of $10 \mathrm{mG}$ and higher [2].

- Prolonged exposure to ELF fields could alter calcium (Ca2+) levels in neurons and induce oxidative stress [13]. It is also possible that prolonged exposure to ELF fields may stimulate neurons (particularly large motor neurons) into synchronous firing, leading to damage by the buildup of toxins. 
From results and public health analysis of the overall existing scientific evidence it can be concluded that new ELF limits are warranted the public health view is that new ELF limits are needed now. They should reflect environmental levels of ELF that have been demonstrated to increase risk for childhood leukemia, and possibly other cancers and neurological diseases. ELF limits should be set below those exposure levels that have been linked in studies to increased risk of disease, plus an additional safety factor [14].

Environmental Health Criteria by WHO stated that the average magnetic field exposures in the workplace have been found to be higher in "electrical occupations" than in other occupations such as office work, ranging from 0.4-0.6 $\mathrm{T}$ (4-6 mG) for electricians and electrical engineers to approximately $1.0 \mathrm{~T}$ for power line workers, with the highest exposures for welders, railway engine drivers and sewing machine operators (above 3 T) . The maximum magnetic field exposures in the workplace can reach approximately $10 \mathrm{mT}$ and this is invariably associated with the presence of conductors carrying high currents [15]

Based upon professional engineering experience and review of the current ELF EMF research literature, VitaTech Engineering recommends $10 \mathrm{mG}\left(\begin{array}{ll}1 & \mathrm{~T}\end{array}\right)$ as a reasonably achievable human exposure limit [8].

\section{Electromagnetic Field Exposure Assessment in Commercial Building:}

In many commercial buildings transformers, electrical line for distribution and other different electrical equipments are placed in the building. Occupied areas above, below, and adjacent to these places may be subjected to very high levels of electromagnetic field. Therefore long-term exposure to high levels electromagnetic field should be considered and avoided. The EMF -ELE in the new commercial building of DEGLA CFM Construction Company, 6 October City have been investigated and evaluated as a case study for environmental impact assessment from electromagnetic field exposure

\subsection{Building Description:}

Impact assessment has been carried out for electromagnetic field emission from electrical equipments (transformer, stabilizer, and main electrical panel, transmission line for distribution and outdoor LED display unit for advertisement. The new commercial building of DEGLA CFM Construction Company, is in 6 October City. The building consists of ground and 4 upper floors. As shown in figure (1). The width of the building is 20 meter and the length is 74 meter. Large LED display installed on the external façade of building as shown in figure (1). The electrical equipments (figure 2) and transmission lines for operating the LED display is placed at first floor. The LED is 
outdoor PH32 mm full color of display size: $73.728 \mathrm{~m}(\mathrm{~W}) * 16.384 \mathrm{~m}(\mathrm{H})$. The transformer is 3 phase distribution transformer type TOC-500/12 - rated voltage 10.500 KV/400V- rated current 2749/721.7 - Hz 50.

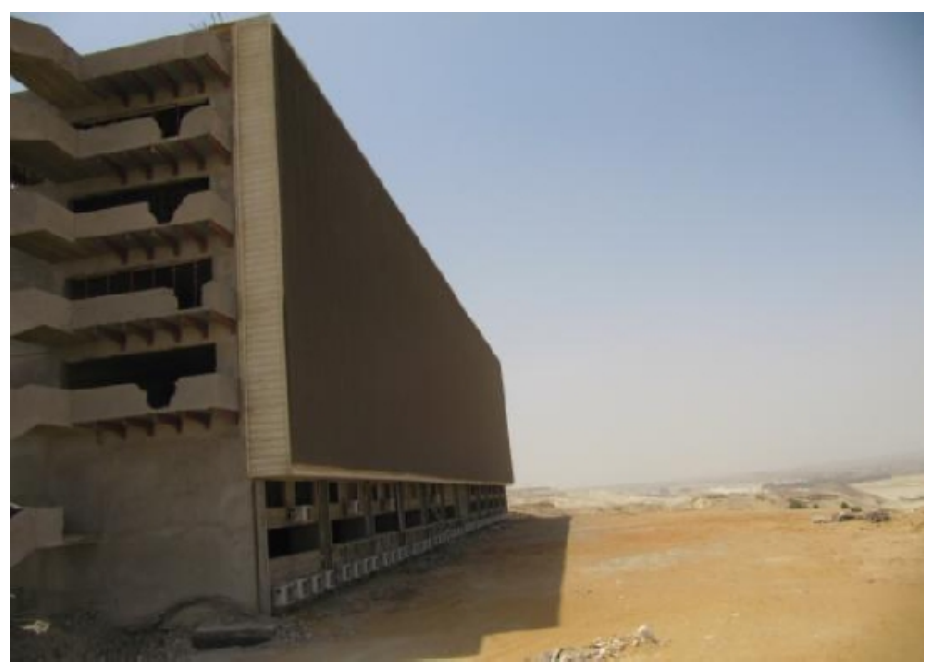

Figure (1:) New building for DEGLA CFM construction company

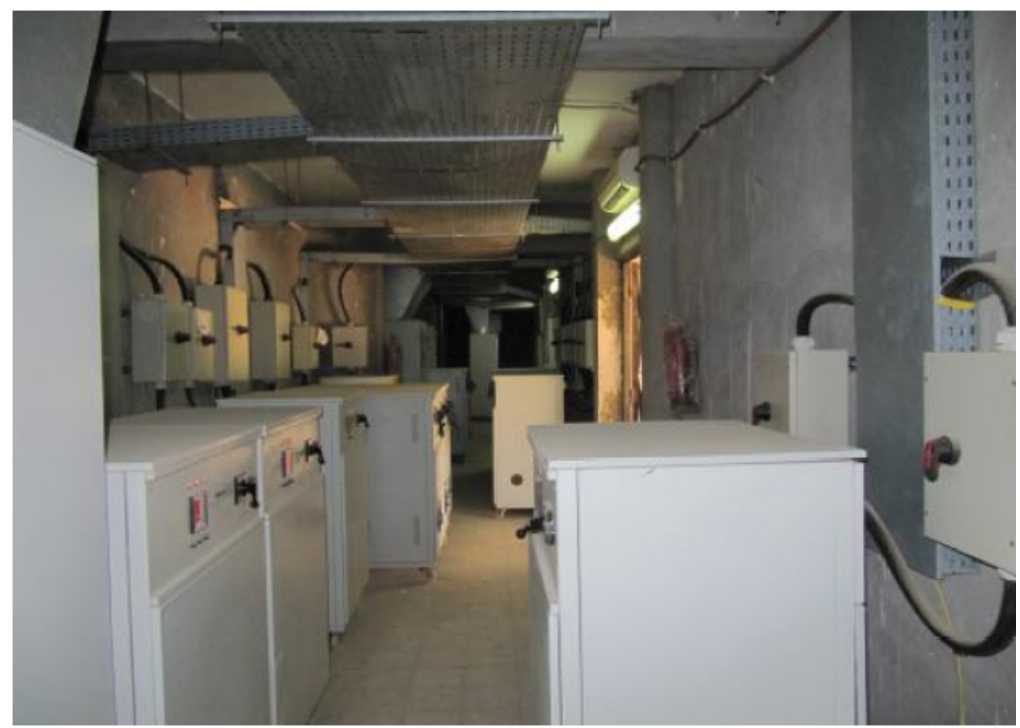




\subsection{Electromagnetic field measurements:}

A digital gauss meter for precise measurement of $\mathrm{AC}$ the electromagnetic field was used. The measurements have been repeated for 4 times in each point and the average was taken in different places inside the building as follows:

\subsubsection{Electromagnetic fields measurements at the ground floor:}

Measurements were taken at different distances away from the wall behind the LED display and in the large area under the room of electrical equipments and control room for operating LED. Table 2 showed the average for each point and table (2) showed the measurement range values at the large area under the room of electrical equipments and control room (ground floor) at different heights from ground.

Table (2): EMF measurements at ground floor directly behind the LED display.

\begin{tabular}{|c|c|}
\hline $\begin{array}{c}\text { Distance } \\
\text { (meter) }\end{array}$ & $\begin{array}{c}\text { Electromagnetic } \\
\text { field (mG) }\end{array}$ \\
\hline \hline 1 & 0.7 \\
\hline 2 & 0.6 \\
\hline 3 & 0.4 \\
\hline 4 & 0.4 \\
\hline 5 & 0.4 \\
\hline 6 & 0.4 \\
\hline 7 & 0.4 \\
\hline 8 & 0.4 \\
\hline 9 & 0.4 \\
\hline
\end{tabular}

Table (3): EMF measurement range values at the large area under the room of electrical equipments and control room (at ground floor)

\begin{tabular}{|c|c|}
\hline $\begin{array}{c}\text { Height } \\
\text { (meter) }\end{array}$ & Electromagnetic field (mG) \\
\hline \hline 2 & $120-90$ \\
\hline 1.5 & $75-65$ \\
\hline 1 & $50-40$ \\
\hline 0.8 & $25-18$ \\
\hline 0.5 & $15-10$ \\
\hline
\end{tabular}




\subsubsection{Electromagnetic fields measurements at the first floor:}

Measurements have been carried out at the first floor inside the room of electrical equipments, large area behind the LED, the corridor and the control room as shown in figure (4). Table (4) showed the EMF measurements in the room of electrical equipments. The EMF at the large area behind the LED display measured at different distances from back wall of the LED display. The EMF measurement values in the large area at the first floor behind the LED display was given in table (5).

Table (4): EMF measurements in the room of electrical equipments at the first floor

\begin{tabular}{|c|c|}
\hline Position & $\begin{array}{c}\text { electromagnetic } \\
\text { field (mG) }\end{array}$ \\
\hline Over the transformer $0.5 \mathrm{~m}$ height & $1650-1800$ \\
\hline center the room & $600-400$ \\
\hline $\begin{array}{l}\text { beside the stabilizers at } 0.5 \mathrm{~m} \\
\text { distance }\end{array}$ & $1000-500$ \\
\hline $\begin{array}{l}\text { beside the transformer at } 0.5 \mathrm{~m} \\
\text { distance }\end{array}$ & $600-450$ \\
\hline $\begin{array}{l}\text { On the front of the main } \\
\text { distribution electric panel at } 0.5 \mathrm{~m} \\
\text { distance }\end{array}$ & $500-350$ \\
\hline
\end{tabular}

Table (5) EMF measurements in the large area behind the LED display at the first floor

\begin{tabular}{|c|c|}
\hline $\begin{array}{c}\text { Distance (meter) } \\
\text { from the wall } \\
\text { back LED }\end{array}$ & $\begin{array}{c}\text { Electromagnetic } \\
\text { field (mG) }\end{array}$ \\
\hline \hline 0.05 & $1800-1990$ \\
\hline 0.15 & $1800-1650$ \\
\hline 0.6 & $125-100$ \\
\hline 0.8 & $75-55$ \\
\hline 1 & $50-35$ \\
\hline 1.5 & $25-10$ \\
\hline 2 & $8-4$ \\
\hline 2.5 & $3-1$ \\
\hline
\end{tabular}

The EMF measurements were carried out in corridor next to the control room and inside the room of electrical equipments and under the transmission line as shown in figure (3). 
EMF was measured at different height from the floor.

Table (6) showed the measurement range values inside the control room that is adjacent to the electrical equipments room. The measurements were carried out at different distances from the separate wall between control room and the room of electrical equipments. The control room contains a computer with flat screen.

Table (6): EMF measurements values under the transmission line at first floor

\begin{tabular}{|c|c|}
\hline $\begin{array}{c}\text { Height } \\
\text { (meter) }\end{array}$ & Electromagnetic field (mG) \\
\hline 2 & $120-100$ \\
\hline 1.5 & $85-65$ \\
\hline 1 & $55-40$ \\
\hline 0.8 & $35-30$ \\
\hline 0.5 & $25-18$ \\
\hline
\end{tabular}

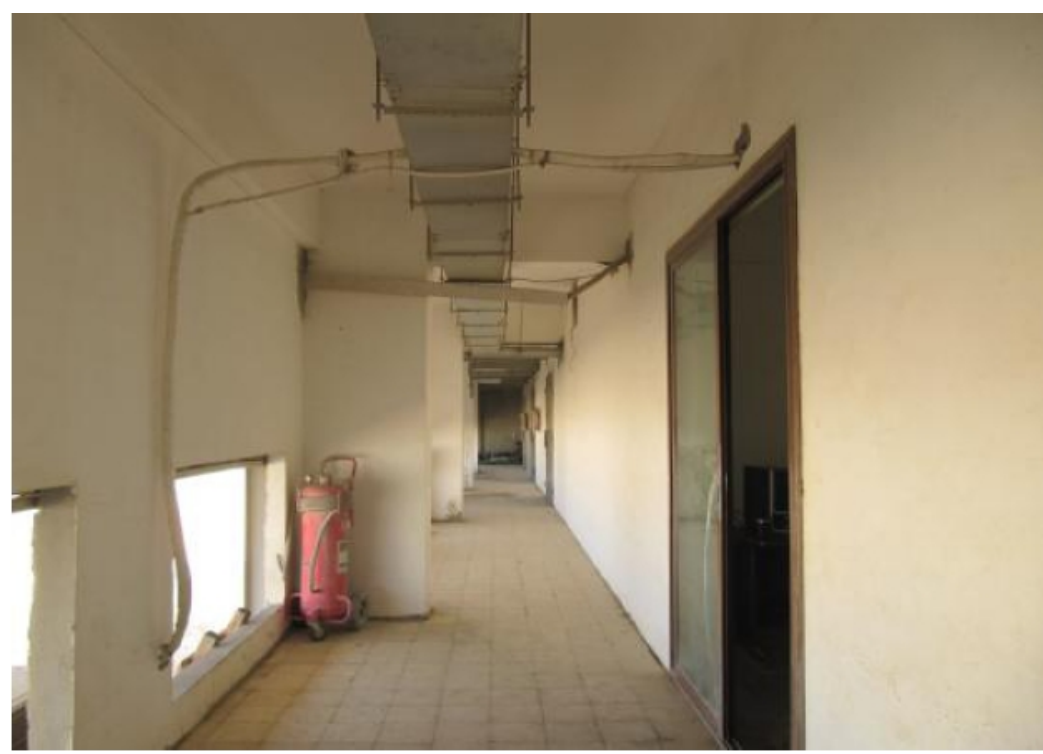


Proceedings of the $\boldsymbol{8}^{\text {th }}$ ICEENG Conference, 29-31 May, 2012

Table (7): EMF measurements values in the control room at first floor

\begin{tabular}{|c|c|}
\hline $\begin{array}{c}\text { Distance from } \\
\text { separate wall } \\
\text { (meter) }\end{array}$ & $\begin{array}{c}\text { Electro-the electromagnetic } \\
\text { field (mG) }\end{array}$ \\
\hline 0.2 & $50-55$ \\
\hline 0.4 & $35-42$ \\
\hline 0.8 & $21-31$ \\
\hline 1 & $10-13$ \\
\hline 2 & $3-5$ \\
\hline
\end{tabular}

LED Display

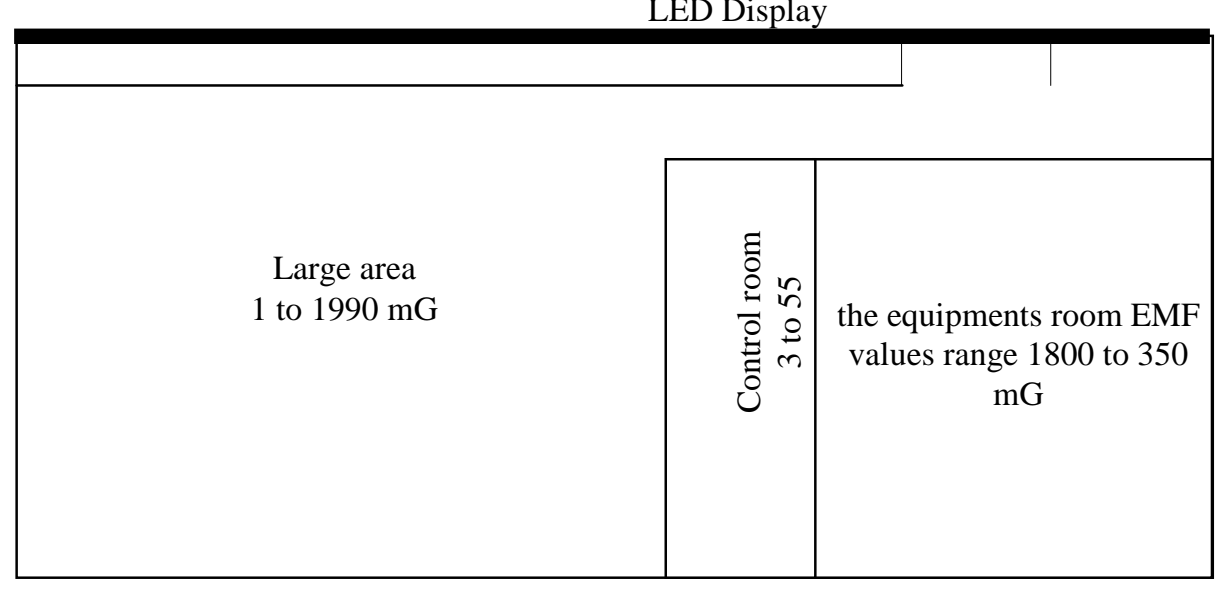

Figure (4): EMF measurement values at the first floor

\subsubsection{EMF measurements at the second, the third and the forth floor}

The EMF measurements were carried out at different points at the second, third and forth floor.

Table (8) summarized EMF measurements 
Table (8): EMF measured range values at second, third and forth floor

\begin{tabular}{|c|c|}
\hline Position & Measured range of EMF \\
\hline \multicolumn{2}{|l|}{ Second floor } \\
\hline Large area & $0.6-0.4$ \\
\hline Area above equipments room & $50-20$ \\
\hline \multicolumn{2}{|l|}{ Third floor } \\
\hline Large area & $0.6-0.4$ \\
\hline Area above equipments room & $10-1.5$ \\
\hline \multicolumn{2}{|l|}{ forth floor } \\
\hline Large area & $0.6-0.4$ \\
\hline Area above equipments room & $1-0.6$ \\
\hline
\end{tabular}

\section{Results and Discussion :}

The main sources of measured EMF in the commercial building were the electrical equipments, transmission lines and LED display. Table 2, 3 showed the measurements results at the ground floor that are lower than the standard reference levels general public in table (1). Table (4) showed the measurements results in room of electrical equipments that are lower than the standard reference levels for occupation as given in table (1). Table (5) showed that the measured values in the large area at the first floor at a distance greater than $60 \mathrm{~cm}$ from the wall behind the LED are lower than the standard reference levels for general public but the values at distance less than $60 \mathrm{~cm}$ from the wall behind the LED are greater than the standard reference levels for occupation as given in table (1). Table (6) showed that the measured values in the corridor under the transmission line are lower than the standard reference levels for occupation and general public. The results from table (7) showed that the measured values in the second, the third, and the fourth floor lower than the standard reference levels for general public. So it can be concluded that EMF measurements in the building is safe for occupational and general public according to international standard given in table 1 except the values at distance less than $60 \mathrm{~cm}$ from the wall behind the LED. On the other hand the problems with existing health standards based on the presumption that induced electric currents in the body are the only concerns when human are exposed to ELE that could be occurs at higher level of EMF. But the safety limits against the bio-effects for health criteria must be considered that could be occurs at lower level of EMF. If EMF criteria of $4-6 \mathrm{mG}$ is considered according to the environmental health criteria by WHO it can be concluded the following measurement values are not accepted specially for long term exposure for general public: 
- All measurements values in the first floor,

- measurements values in the area under the room of electrical equipments in the ground floor

- measurement values above the room of electrical equipments the in second and third floor

So EMF can be mitigated in these places by the following methods:

- increase the distance between the source of EMF and occupation

- The room of electrical equipments can be shielded by using panel of ferromagnetic mumetal alloy composed of $80 \%$ nickel and 20\% iron [8].

EMF emitted from the back of LED can be shielded by adding panel of ferromagnetic mumetal alloy composed of $80 \%$ nickel and $20 \%$ iron behind LED display

\section{Conclusion}

Several recent research studied the bio-effects of EMF of low frequency on health and indicated the interaction between exposure to magnetic fields and the risk of cancer, leukemia, brain tumors and many other bio-effects. The existing international standard limits for electromagnetic field exposure are not adequate for health because these limits are based on the presumption that induced electric currents in the body are the only concerns when living organisms are exposed to ELE. Lower limits are needed to reduce possible public health risks in the future.

Also this paper investigates the power frequency electromagnetic fields exposure from electrical equipments, main electrical panel, transmission lines and LED display in a commercial building as a case study for magnetic field exposure assessment. All electromagnetic field measurements in the buildings are lower than the existing international standard reference levels for occupation and general public. On the other hand the measurement values were compared to more safety limit of 4-6 mG as health criteria to reduce possible public health risks in the future. The measurements values in the room of electrical equipments or in places adjacent, above and under the room of electrical equipments are not accepted for general public. Also places directly behind the LED display are not accepted for general public exposure.

For mitigation the high level of EMF, the sources must be located away from the work area for general public. Also the room of electrical equipments and the LED display can be shielded by using panel of ferromagnetic mumetal alloy composed of $80 \%$ nickel and $20 \%$ iron. 


\section{Reference}

[1] Static and Extremely Low-Frequency (ELF) Electric and Magnetic Fields NonIonizing Radiation, Part 1, Volume 80

[2] BioInitiative Report: A Rationale for a Biologically-based Public Exposure Standard for Electromagnetic Fields (ELF and RF)

[3] International Commission on Non-Ionizing Radiation Protection (ICNIRP) Guidelines for limiting exposure to time-varying electric, magnetic, and electromagnetic fields (up to $300 \mathrm{GHz}$ ). Health Phys 1988, Vol74, No 4, 494522.

[4] International Commission on Non-Ionizing Radiation Protection (ICNIRP) Guidelines for limiting exposure to time-varying electric, magnetic, and electromagnetic fields ( $1 \mathrm{~Hz}$ to $100 \mathrm{~K} \mathrm{~Hz}$ ), Health Phys, 2002

[5] Institute of Electrical and Electronics Engineers (IEEE). IEEE PC95.6-2002 standard for safety levels with respect to human exposure to electromagnetic fields, 0 to $3 \mathrm{kHz}$. Prepared by Subcommittee III of Standards Coordinating Committee 28, IEEE Standards Department. New York: Institute of Electrical and Electronics Engineers, Inc.; 2002

[6] (1999/519/EC) COUNCIL RECOMMENDATION On the limitation of exposure of the general public to electromagnetic fields $(0 \mathrm{~Hz}$ to $300 \mathrm{GHz})$, Official Journal of the European Communities, July 1999

[7] DIRECTIVE 2004/40/EC OF THE EUROPEAN PARLIAMENT AND OF THE COUNCIL on the minimum health and safety requirements regarding the exposure of workers to the risks arising from physical agents (electromagnetic fields), Journal of the European Communities, April, 2004

[8] Louis S. Vitale, President \& Chief Engineer " Guide To Solving AC Power EMF Problems In Commercial Buildings, August 1995, Revised May 10, 2008, VitaTech Engineering, LLC 8

[9] M.L. Coleman, A review of epidemiologic studies of the health effects of living near or working with electricity generation and transmission equipment, Int. J. Epidemiol. 17 (1988) 1-13.

[10] S. Perry, L. Pearl, Power frequency magnetic field and illness in, multi-storey blocks, Public Health 102 (1988) 11-18

[11] J.R. Thomas, et al., Low-intensity magnetic fields alter operant, behavior in rats, Bioelectromagnetics 7 (1986) 349-357.

[12] World Health Organization, 2007. ELF Health Criteria Monograph, page 256 and WHO Fact Sheet No. 322.

[13] World Health Organization, 2007. ELF Health Criteria Monograph. Neurodegenerative, Disorders, Page 187.

[14] S. Amy Sage, BioInitiative Report: A Rationale for a Biologically-based Public 
Exposure Standard for Electromagnetic Fields (ELF and RF), Cindy Sage, MA Sage Associates, USA august, 2007

[15] World Health Organization, "Environmental Health Criteria 238" 2007 